\title{
Management of Various Safety Parameters in Tunnel Construction: A Critical Review
}

\author{
Priyanka Omar $^{l *}$, MVN. Siva Kumar ${ }^{l}$, Subbarao Yarramsetty ${ }^{l}$ \\ ${ }^{l}$ Department of Civil Engineering, NIT Warangal, Telangana State-506 004, India.
}

\begin{abstract}
Population is growing rapidly and so are vehicles on roads. This leads to enormous need of tunnels and subways for easy locomotion and mobilization. From conventional tunnels, for sewage and water facilities to modern electrified tunnels, for mass transit and underwater highways, method of construction of a tunnel to its safety inspection and maintenance has taken a wide leap. Tunnel construction requires wide range of resources like human, technology, machinery, materials, energy, and finance. To handle all these resources simultaneously becomes complex and requires good management. Even with good management, accidents and hazards might occur. A critical review of various safety parameters while constructing a tunnel and its management is presented in this paper. This review paper discusses the history of safety of tunnels till present safety measures and techniques adopted around the world for different tunnels; various critical factors which affect the safety in tunnels; the extent of damage occurring due to these factors; numerous preventive measures which are adopted around the world to prevent loss of property and lives in tunnels; and advanced technology and software, which are being used in modern era to enhance safety in tunnel construction. The study from manual horse drawn-tramway to autonomous robotic system has been done. This paper also considers various tunnels around the world and gives a summary of factors for safety focused on for making these tunnels, with its adopted remedy.
\end{abstract}

\section{Introduction}

Present day tunnels differ completely from what they were in the past. From their usage to their construction practices, everything got evolved drastically. Trench digging was the most common conventional method used for constructing tunnels for waterways. In 1681, France used first power drove method of the form explosives and Nitro-glycerine dynamites, for drill and blasting. Due to lack of skill, knowledge and experience in construction fields, many others started focusing on human resource and machine management, which plays a crucial role in complex areas of tunnel constructions. With further increase in population and mobility, risks of accidents increased, and thereby power and safety management too started getting limelight, for better locomotion. And for making innovative tunnels, as a major source of attraction for tourists; cost, design and economy was also being focused. Tunnel construction deals with lots of initial challenges, as shown in fig.1. (a) For proper work order of all these conditions, skilled and unskilled human resources are needed, whose health and safety should be properly controlled on site. Many theories have been given for maintaining a good working environment. Many short time parameters like, vehicle speed, wind speed, wind direction, mix and age, play a crucial role than long time parameters like, monitoring and controlling, as latter ones are often hindered.

\footnotetext{
*Corresponding author: priyanka@student.nitw.ac.in
}

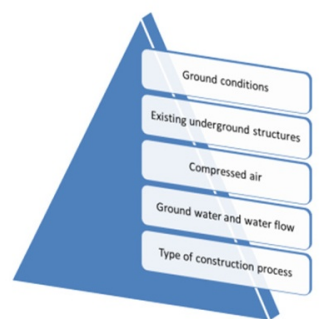

(a)

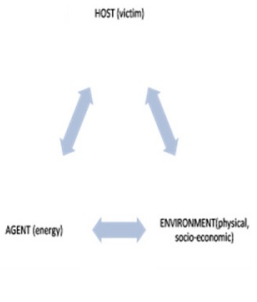

(b)
Fig.1. (a) Challenges triangle, (b) Epidemiological triangle

Fig.1. (b) shows epidemiological triangle which is a model for controlling the spread of infectious diseases during the 19th century in Europe. By controlling one of the factors of this triangle, spread can be controlled. The same theory is also applicable in underground construction. Hence, it is essential to control factors like damaging of surface structures, settlements (before and after excavations), reduction in strength of concrete with aging, cracks due to vibration of moving vehicles, fire hazards due to freight carried by the trucks and many other factors, which are discussed further, in underground construction [1].

Various researches and publications have been made in the past years related to tunnel and its safety. Fig. 2 shows the number of publications versus year of publication graph. From the past five decades, around 
forty thousand publications have been published on various internet sources, with maximum number of publications done in Springer, followed by ASCE (American Society of Civil Engineering) and Taylor and Francis.

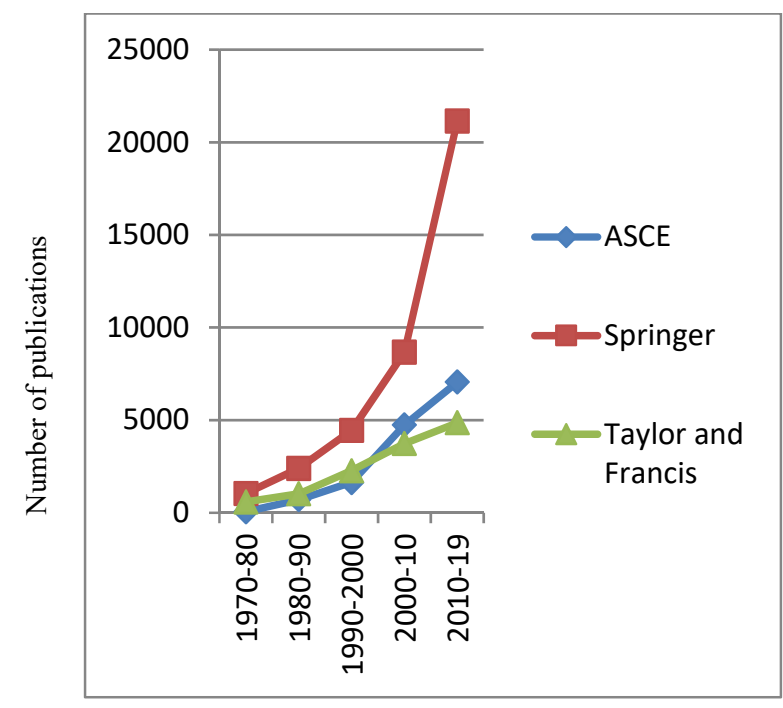

Year of publication

Fig.2. Graph showing past publications in tunnels

\section{Progress of tunnel safety}

Proper documentation of progress, resources used, construction methods, equipments, quality analysis, safety, site conditions, building information, data entry of manpower, quantity of materials and details, shall be done while constructing a tunnel, which can even reduce future disputes.

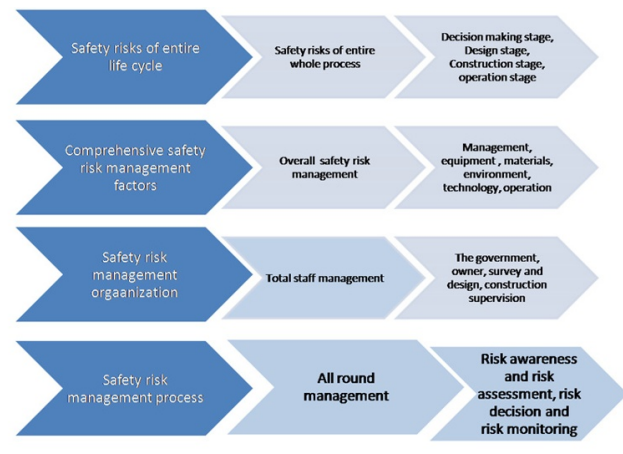

Fig.3. Methodology adopted by China for underground engineering

Fig.3. shows the procedure how China manages safety risk. Many companies now keep a track of all activities like approve payments, update schedules, field/shop adjustments, quality control using advanced computerbased software for our betterment and swiftness. Proper energy analysis has been done of cutter head drives, shield operations and various nonlinear parameters, which has become a challenge for tunnel engineers [2]. Various factors in the process of excavation like type of foundation, depth of tunnel section, size, geometric characteristics, makes it difficult to take risk management of each and every building [3]. For economic analysis, many designers have adopted dynamic soil parameters which were resulted from good ground investigation and soil testing. To reduce the impact of explosion for bomb type tunnel construction, fine protective layer over tunnel structure is proposed rather than constructing cost effective tunnels [4]. Earth pressure balanced shield machine (EPBS) is very efficient and economical for underground construction of metro tunnel in urban areas [5]. Displacement monitoring has become more important regulating factor based upon primary soil parameters. Electric heat tracing method is most widely used for frost damage tunnels and tunnels in cold regions [6]. Tunnel ventilation is one of the major factors which is often neglected. Natural and renewable wind has been used to produce power for proper ventilation of long tunnels at the tunnel construction site. Optimized energy consumption and feasible solutions have been given for maintaining proper ventilation inside the tunnel [7]. The main factor for initiating any construction is Communication [8].

\section{Extent of damage in tunnels}

Train tunnel fires are more devastating than road tunnel fires, due to wide mobilization of freights. Still the former ones are frequently used for easy locomotion, keeping the aim to reduce the risk of fatalities [9]. With growing population and vehicles, the safety of tunnels is a major concern. The major factors which contribute towards safety in an underground construction can be listed as:

1. Human health and accidental factors

2. Environmental factors

3. Technical factors

According to UNESCO [10], the level of tunnel safety can be classified into following groups:

1. Road users

2. Infrastructure

3. Operation

4. Vehicles

Drainage systems have been made adequate in design to avoid contact of water with the structure and added pressure on side walls and concrete slabs. This will reduce the maintenance costs of tunnels [11]. Shanghai has used grouting based treatment method for preventing the settlement in soft deposits. It has shown reduction in tunnel settlement rate and prevented further settlement [12]. Some of the important factors which can be used in advancing an underwater tunnel construction include: (1) Error-free forecasting of the topographical conditions and oozing characteristics of water lying ahead of the working portion; (2) High pressure water gushes shall be prevented [13]. 
The casualty factor as given by UNESCO is shown in Table 1, for the pre-calculation of risk and the extent of damage caused by several categories of transportation modes.

Table 1.Fatality factor adopted for calculation of risk

\begin{tabular}{|c|c|}
\hline Mode of transportation & $\begin{array}{c}\text { Casualties per 109 } \\
\text { passenger- kms }\end{array}$ \\
\hline Airline & 0.06 \\
\hline Railway & 0.1 \\
\hline Bus/coach occupant & 0.19 \\
\hline Maritime vessel & 0.27 \\
\hline Occupant & 2.67 \\
\hline Automobile motorist & 1.82 \\
\hline Automobile traveller & 0.85 \\
\hline Fuelled two wheeler & 37.8 \\
\hline
\end{tabular}

There is a high degree of uncertainty in underground cavern groups as it has been observed that they commonly fail due to variation in construction over time. A key factor for determining 3D simulations is the uncertainty in construction and geological processes [14]. A number of hazards are being faced by human workforce during grouting operations. Grouting work consists of three major stages: 1) Involvement of powerful hydraulic and pneumatic drilling machines for drilling; 2) Usage of agitators and mixers of numerous capacities for mixing process; and 3) Usage of different capacity pumps for better output in pumping [15].

Floods are another factor which causes hindrance in tunnel construction. Detailed study has been conducted elicited on region wise flood risk assessment technique archives, which includes (a) statistical methods, (b) analysis using remote sensing (RS) and/or geographical information system (GIS),(c) multi-criteria analysis, and (d) scenario-based analysis. A perspective approach based on evaluation of overflowing risk of tunnel systems has been proposed. This approach has the following two characteristics: - from local to global, and from qualification to quantification. Overflow risk in tunnels is handled through the mix usage of GIS, satellite-based radio navigation systems like global position system (GPS) or our indigenously developed Indian Regional Navigation Satellite System (IRNSS): NavIC and build information modelling (BIM) has also been proposed [16]. Tunnel Dismantling Machine is as important as Tunnel Boring Machine [17].

Noise-induced hearing loss had been occurred among $92 \%$ of the tunnel constructing manpower [18]. There is lack of occupational medicine and industrial hygiene system with a low awareness of health and safety issues at all levels of management at many tunnel constructing sites. There should be a good functioning regulatory body, proper client supervision and sophisticated trade unions, which should have a high priority in construction project.

\section{Critical conditions of focus}

Many serious pollutants have both short and long term exposure, affecting the health of humans. For this, air quality standards have been set for minimizing health impact [19]. There should be rigorous distinction between 'core' and 'peripheral' staff, with a distinction between soft and hard human resource management as well [20].

There should be a strict distribution of the explosives into the rock and a specific drilling pattern should be followed for good blasting results. When designing the drilling pattern, several factors must be taken into account like rock drill and blast ability, type of explosives, restrictions in blast vibration and error-free requirements of the blasted wall etc [21]. In the process of localized tunnel construction, water table causes mud inrush; cost of construction, stability of the tunnel, schedule and safety, all gets affected by landslides and rock collapse [22]. The major step of construction that should be concentrated upon while controlling tunnel digging is the blasting. While constructing new tunnels, monitored value of blasting vibration of already made tunnels (maximum velocity) can be used in design parameters to lessen the impact of vibration [23].

Face stability is very critical point which should be kept in mind for the safety of underwater construction across fault zones [24]. Due to the complex nature of the tunnels, various important parameters had been noted for the sound operation of tunnel network. These parameters include the traffic, the behaviour of the people trapped there during evacuation, the latency of the tunnel personnel in traffic interruption or activating the mechanical ventilation, fire behaviour and the natural environmental conditions. While driving, drivers in road tunnels will gradually reduce their speed and increase their lateral position from the respective tunnel wall while driving [25]. Flame hindering on highway tunnel pavement made from asphalt shall be taken into account for constructing the tunnels [26].

Table 2.Parameters for tunnel design affected by various categories

\begin{tabular}{|c|c|}
\hline Category & Parameter \\
\hline Tunnel attributes & Gradient, Geometry, Ventilation \\
\hline Vehicle fleet attributes & $\begin{array}{c}\text { Age and mix, Emission } \\
\text { Standards, Fuel quality, Engine } \\
\text { type }\end{array}$ \\
\hline Automobile operations & $\begin{array}{c}\text { Stop and go traffic, Traffic } \\
\text { density, Temperature, Inspection } \\
\text { and maintenance }\end{array}$ \\
\hline
\end{tabular}

Table 2 gives a summary of parameters which should be taken care of while constructing the tunnel. Each of these parameters shall have an equivalent focus while designing the tunnels. 


\section{Preventive measures}

Assumption of sequential accident process was made and major development took place since the Second World War for a number of safety analysis techniques [27]. Incorporation of risk-based analysis to safeguard and control had been proposed which can be classified into qualitative and quantitative risk analyses, to prevent heavy casualties and property losses resulting from safety violations [28]. Attempt had been made to formulate the basic event data as a fuzzy probability set and using them in subsequent computation [29]. A feasible method of adoption of the semi-quantitative analysis had been taken into effect. For underwater tunnels, methods which can be adopted are wire line engineering method, reverse method, double pipe reversing engineering method, pressure boring method, air boring method and grouting [13].

To release strain energy, it is relevant to induce spalling with a long period over roof and spandrel, whenever there is lower lateral pressure coefficient [30]. For preliminary check-up of underground conditions in the Himalayan region, a novel multiple-graph technique had been proposed. This technique is based on the estimation of three quantities, i.e. the ground condition, competency factor and rock mass strength [31].

Due to vulnerability in ground shaking, post-earthquake investigations had shown that tunnels are exposed to seismic risk [32]. Inclusion of mandated concepts and reactions shall be done for the driving licensing procedure of long tunnels and implementation of driving safety education should also be done for improving long tunnel safety. The designers should keep in mind the environmental influence while designing tunnels [33]. Fig 4 shows functioning inside a tunnel for proper alignment when engineers do not know the centre line during construction. People are very much concerned regarding the safety aspects of vehicular tunnels because of a severe past fire in Hong Kong, resulting from a truck carrying diesel outside a tunnel [34]. To prevent the loss of visual adaptation, proposal of an optical coupling of networked tunnels with translucent red structures shall be executed to weakly lit environments [35]. During tunnelling, radon level can be on the high side especially where poor ventilation is forecasted. Radon content in tunnel environment is found to be due to ventilation provision, groundwater ingress and topographical and geological factors. The situation had been improved a lot through the adoption of control legislation, education and more specifically, improvising of radon management plan in every tunnel drilling project [36].

Underground workplaces are a crucial element in modern urban planning. Proper research needs to be done on the health implications and the probable environmental vulnerability, to envisage future research paths including effects of artificial lighting particularly night time exposure to short wavelength (blue) light (light at night) and shift working, associated health effects, sleeplessness and circadian rhythm disruptions. Risks are manifold when exposed to working underground and may be linked to hypovitaminosis D, excessive noise, radar exposure and negative psychological effects.

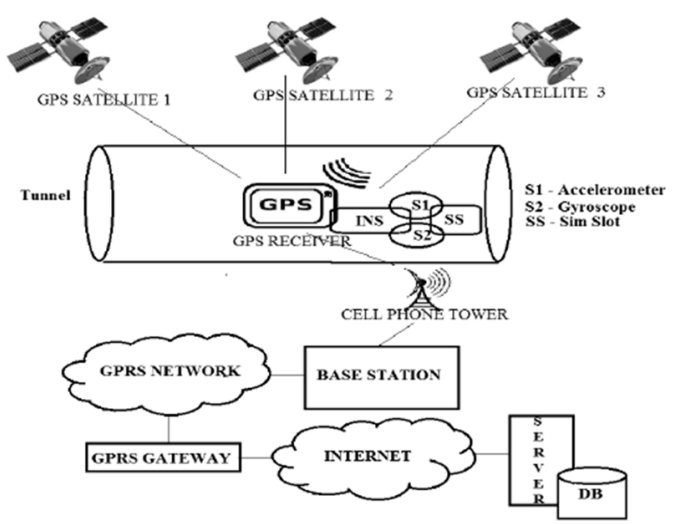

(a)

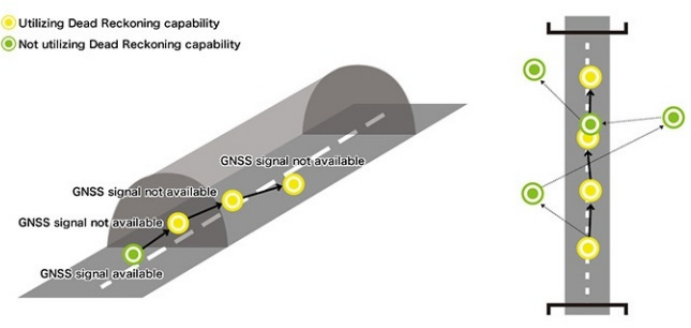

(b)

Fig.4. (a) GPS adoption for a tunnel construction, (b) ground tracking in tunnels where the GPS/GNSS signals are shielded and unavailable.

Research needs to be done on the health effects of underground environments so as to plan safety measures and remedial action accordingly [37].

\section{Application of advanced technology to improve safety}

Under well-controlled conditions, dynamometer-based emission factors are measured where proper monitoring of different emission-influencing parameters are done [19]. Serious efforts are involved in physical, analytical, or numerical models. Installation of durable and robust sensors enabled intelligent prediction and monitoring of real time behaviour of underground structures [25]. Introduction of a real-time online safety analysis approach which is based on four-dimensional technology, done during the construction of tunnel had been done. The 4D construction safety information models very well established, since it gives the complete 
picture of dynamic bond between the structural system and the construction process information, and thus are being widely used for rapid and automatic generation of 3D models. A structural analysis model with the construction schedule and material information can also be done.

There is a dearth of experience in implementation of construction management in underdeveloped nations. To improve the functioning of management, evaluation of human resource management processes shall be done in construction project, which should use inputs, outputs, utilities and tools and techniques recommended by the Guide to the Project Management Body of Knowledge (PMBOK, 2004) [38]. Numerous technologies had been adopted for the construction safety, including sensorbased technology, information communication technology, radio frequency identification, 3S (GIS/GPS/RS) technology, and virtual reality. With the proper usage of advanced seismic wave propagation modelling software SPECFEM2D, ample number of studies had been conducted on ground motion behaviour around excavations via analysis of velocity wave fields, PPV contours, and amplification factors under different k/D ratios. Both the loading conditions, "quasi-static" and "dynamic interaction", had been considered in the modelling analysis [39].

Extra safety measures should be provided during the remedial work. Installations like exhaust air blinds in the area prone to fire for full ventilation power and for emergency niches, a compressed air system shall be well equipped at the tunnel site [40]. The special light zones could help relieve drivers' vision tiredness to some extent and moreover develop certain optical stimulus that can intensify drivers' attention [41]. Building information models (BIMs) has the ability to support information accoutring over the entire lifecycle of infrastructure assets [42].

One of the main inferences that could be drawn out is that nine usual risk factors for mechanical tunnelling had been identified, i.e. excavation of tunnel, launching of TBM, segment assembly, special procedures and conditions, arrival of TBM, grouting, pilot excavation, mucking, and shaft construction [43]. Effects of TBM excavation rate can be analyzed by special laboratory testing which uses numerical models based on elastovisco-plastic constitutive law. An important step of TBM tunnelling with segmental concrete lining has been taken towards hydroelectric power development and better transportation, especially in Himalayan regions of India. [44].

\section{Discussions and Conclusion}

Table 3 summarizes all the past tunnels with their adopted remedies.

Table 3. Tunnels constructed in past with adopted remedies

\begin{tabular}{|c|c|}
\hline Tunnel name & Remedy \\
\hline $\begin{array}{l}\text { Tunnel beside Taipei } \\
\text { Songshan airport }\end{array}$ & $\begin{array}{c}\text { Adoption of } \\
\text { dynamic soil parameters, } \\
\text { obtained from good } \\
\text { ground investigation and } \\
\text { soil testing } \\
\end{array}$ \\
\hline $\begin{array}{l}\text { Burata Railway } \\
\text { Tunnel, Spain }\end{array}$ & $\begin{array}{c}\text { Manual lowering of the } \\
\text { water level }\end{array}$ \\
\hline $\begin{array}{l}\text { Shield tunnels under } \\
\text { the Huangpu } \\
\text { River of Shanghai }\end{array}$ & $\begin{array}{c}\text { For joint sealing, } \\
\text { preference of gasket } \\
\text { sealing over paint sealing }\end{array}$ \\
\hline $\begin{array}{c}\text { Environmental } \\
\text { effects of tunnel } \\
\text { excavation in soft } \\
\text { and shallow ground } \\
\text { with EPBM: the } \\
\text { case of Istanbul } \\
\end{array}$ & $\begin{array}{c}\text { Tunnels were excavated by } \\
\text { using two Earth Pressure } \\
\text { Balance Tunnel Boring } \\
\text { Machines }\end{array}$ \\
\hline $\begin{array}{l}\text { Safety management } \\
\text { in tunnel } \\
\text { construction: Case } \\
\text { study of Wuhan } \\
\text { metro construction } \\
\text { in China } \\
\end{array}$ & $\begin{array}{l}\text { ANSYS finite element } \\
\text { software was employed to } \\
\text { simulate a numerical } \\
\text { model of the drilling } \\
\text { process }\end{array}$ \\
\hline $\begin{array}{l}\text { Qingdao Metro } \\
\text { subway tunnel }\end{array}$ & $\begin{array}{l}\text { Grouting method was used } \\
\text { to improve collapse- } \\
\text { preventing treatment in the } \\
\text { sand layer }\end{array}$ \\
\hline Niayesh tunnel & $\begin{array}{l}\text { Sequential excavation } \\
\text { method (SEM) was } \\
\text { selected for tunnel } \\
\text { construction }\end{array}$ \\
\hline $\begin{array}{c}\text { MTR West Island } \\
\text { Line (WIL) project } \\
\text { and Overrun Tunnel } \\
\text { (ORT }\end{array}$ & $\begin{array}{l}\text { a customised tunnel } \\
\text { dismantling machine } \\
\text { (TDM) was innovated }\end{array}$ \\
\hline Seikan Tunnel & $\begin{array}{l}\text { Pilot boring and grouting } \\
\text { methods used }\end{array}$ \\
\hline
\end{tabular}

After reviewing all the contents and publications on tunnel safety, following conclusions can be drawn out:

- China has shown an extent of development in tunnel engineering, which can help the world take a leap in tunnel construction and reducing the risks in its formation.

- Various factors like passengers, mode of transportation, type of tunnels and its usage, emissions caused by fuels inside the tunnels, etc. shall be considered while making studies for tunnel construction.

- Fire is one of the most hazardous factors which shall be taken care of. Proper fire prevention equipments and remedies shall be implemented at the tunnel site.

- Other factors like human resource management, technical factors, and environmental factors, shall be studied and analyzed well before hand, to avoid any serious damage or accidents. 
A number of studies have proved that the tunnel can be used as a short-time shelter if a seismic secondary disaster such as landslide or avalanche occurs. It can also act as an important route for postdisaster rescue operations. Various diversified, innovative and continuous technologies have come to ensure tunnel safety during its construction. The extent of damage due to carriage of goods shall be taken into account and should be made safer to prevent fire hazards. Design safety, monitoring and safety information shall be kept updated by researchers and tunnel engineers. Strictly speaking, tunnel construction safety management is a crucial process of safety information collection, scheduling, transmission, storage, analysis, evaluation and response which should be done efficiently.

\section{References}

1. I. Ocak, Environ. Earth Sci. 59, 347 (2009).

2. X. Li and H. Zhu, (2013).

3. J. Chen, J. Yang, H. Wang, B. Liu, and X. Yang, Geotech. Spec. Publ. 211 (2009).

4. M. W. Gui and M. C. Chien, Geotech. Geol. Eng. 24, 227 (2006).

5. F. Meng, R. Chen, and X. Kang, Tunn. Undergr. Sp. Technol. 80, 53 (2018).

6. Z. Hu, H. Ding, J. Lai, H. Wang, X. Wang, and S. He, Constr. Build. Mater. 185, 670 (2018).

7. C. Guo, M. Wang, L. Yang, Z. Sun, Y. Zhang, and J. $\mathrm{Xu}$, Renew. Sustain. Energy Rev. 53, 1558 (2016). 8. J. K. Lemley, Tunn. Undergr. Sp. Technol. 10, 9 (1995).

9. M. S. Tomar and S. Khurana, Tunn. Undergr. Sp.

Technol. 85, 149 (2019).

10. I. T. Committee, Group 1 (2001).

11. Osama Bedair, Pract. Period. Struct. Des. Constr. 16, 73 (2011).

12. D. M. Zhang, Z. K. Huang, R. L. Wang, J. Y. Yan, and J. Zhang, Tunn. Undergr. Sp. Technol. (2018).

13. B. A. Kitamura and Y. Takeuchi, 109, 25 (1983).

14. H. Salehi and R. Burgueño, Eng. Struct. 171, 170 (2018).

15. K. R. Al-Labadi, H. M. Al-Humaidi, and F. H. Tan, J. Perform. Constr. Facil. 23, 423 (2009).

16. H. M. Lyu, S. L. Shen, A. Zhou, and J. Yang, Tunn. Undergr. Sp. Technol. 84, 31 (2019).

17. P. L. Ng, T. N. D. R. Barrett, G. Roux, S. Polycarpe, and M. Gonzalez, Procedia Eng. 189, 560 (2017).

18. F. Chen, H. Peng, X. Ma, J. Liang, W. Hao, and X. Pan, Tunn. Undergr. Sp. Technol. 92, 103034 (2019). 19. P. Taylor and Z. Hashisho, Critical Reviews in Environmental Science and Technology Vehicular Emissions in Roadway Tunnels : A Critical Review Vehicular Emissions in Roadway Tunnels : A Critical Review (n.d.).

20. C. Greed, Constr. Manag. Econ. 31, 197 (2013).

21. A. Balasubramanian, (2017).

22. C. López-Fernández, D. A. Prieto, G. Fernández-

Viejo, L. Pando, and E. C. Fernández, J. Geotech.

Geoenvironmental Eng. 139, 821 (2013).
23. D. Chen and S. Xu, Proc. 2nd Int. Conf. Transp. Eng. ICTE 2009 2009, 3748 (2009).

24. M. Karakus and R. J. Fowell, Tunn. Undergr. Sp.

Technol. 18, 513 (2003).

25. S. Bassan, IATSS Res. 40, 35 (2016).

26. J. Qiu, T. Yang, X. Wang, L. Wang, and G. Zhang, Constr. Build. Mater. 195, 468 (2019).

27. P. Swuste, C. van Gulijk, W. Zwaard, and Y.

Oostendorp, Saf. Sci. (2014).

28. Q. Qian and P. Lin, J. Rock Mech. Geotech. Eng. 8, 423 (2016).

29. S. K. Ayer, G. A. Macht, R. M. Leicht, and A.

David, 349 (2014).

30. M. Tao, H. Zhao, X. Li, J. Ma, K. Du, and X. Xie, Geomech. Eng. 12, 1 (2017).

31. D. Majumder, M. N. Viladkar, and M. Singh, Int. J.

Rock Mech. Min. Sci. 100, 278 (2017).

32. G. Andreotti and C. G. Lai, Tunn. Undergr. Sp.

Technol. 91, (2019).

33. T. I. Airport, T. County, T. County, L. District, and N. T. City, 78 (2014).

34. W. K. Chow, Review on Fire Safety Management and Application to Hong Kong (2001).

35. A. Peña-García, Tunn. Undergr. Sp. Technol. 91, 103007 (2019).

36. K. Y. K. Li, A. T. Chan, and M. Asce, (n.d.).

37. N. Ei, E. Khaing, G. Abuduxike, P. Posadzki, U.

Divakar, N. Visvalingam, N. Nazeha, G. Dunleavy, G. I.

Christopoulos, C. Soh, K. Jarbrink, M. Soljak, and J.

Car, 84, 201 (2019).

38. K. El-dash, 65 (2007).

39. C. Li and X. Li, Int. J. Rock Mech. Min. Sci. 112, 323 (2018).

40. A. Leitner, Tunn. Undergr. Sp. Technol. 16, 217 (2001).

41. Y. Yan, X. Wang, L. Shi, and H. Liu, 9588, (2017).

42. N. Vossebeld and T. Hartmann, 57 (2014).

43. W. Liu, T. Zhao, W. Zhou, and J. Tang, Saf. Sci. 105, 98 (2018).

44. N. Swannell, M. Palmer, G. Barla, and M. Barla, Tunn. Undergr. Sp. Technol. Inc. Trenchless Technol. Res. 57, 201 (2016). 